\title{
Primary versus secondary source of data in observational studies and heterogeneity in meta-analyses of drug effects: a survey of major medical journals
}

Guillermo Prada-Ramallal 1,2, Fatima Roque ${ }^{3,4}$, Maria Teresa Herdeiro 5,6, Bahi Takkouche ${ }^{1,2,7}$ and Adolfo Figueiras ${ }^{1,2,7^{*}}$ (D)

\begin{abstract}
Background: The data from individual observational studies included in meta-analyses of drug effects are collected either from ad hoc methods (i.e. "primary data") or databases that were established for non-research purposes (i.e. "secondary data"). The use of secondary sources may be prone to measurement bias and confounding due to overthe-counter and out-of-pocket drug consumption, or non-adherence to treatment. In fact, it has been noted that failing to consider the origin of the data as a potential cause of heterogeneity may change the conclusions of a meta-analysis. We aimed to assess to what extent the origin of data is explored as a source of heterogeneity in meta-analyses of observational studies.

Methods: We searched for meta-analyses of drugs effects published between 2012 and 2018 in general and internal medicine journals with an impact factor $>15$. We evaluated, when reported, the type of data source (primary vs secondary) used in the individual observational studies included in each meta-analysis, and the exposure- and outcome-related variables included in sensitivity, subgroup or meta-regression analyses.
\end{abstract}

Results: We found 217 articles, 23 of which fulfilled our eligibility criteria. Eight meta-analyses (8/23, 34.8\%) reported the source of data. Three meta-analyses $(3 / 23,13.0 \%)$ included the method of outcome assessment as a variable in the analysis of heterogeneity, and only one compared and discussed the results considering the different sources of data (primary vs secondary).

Conclusions: In meta-analyses of drug effects published in seven high impact general medicine journals, the origin of the data, either primary or secondary, is underexplored as a source of heterogeneity.

Keywords: Observational studies, Meta-analysis, Source of data, Heterogeneity, Drug, Over-the-counter, Out-of-pocket

\section{Background}

Specific research questions are ideally answered through tailor-made studies. Although these ad hoc studies provide more accurate and updated data, designing a completely new project may not represent a feasible

\footnotetext{
* Correspondence: adolfo.figueiras@usc.es

'Department of Preventive Medicine and Public Health, University of Santiago de Compostela, c/ San Francisco s/n, 15786 Santiago de Compostela, A Coruña, Spain

${ }^{2}$ Health Research Institute of Santiago de Compostela (Instituto de Investigación Sanitaria de Santiago de Compostela - IDIS), Clinical University Hospital of Santiago de Compostela, 15706 Santiago de Compostela, Spain Full list of author information is available at the end of the article
}

strategy $[1,2]$. On the other hand, clinical and administrative databases used for billing and other fiscal purposes (i.e. "secondary data") are a valuable resource as an alternative to ad hoc methods (i.e. "primary data") since it is easier and less costly to reuse the information than collecting it anew [3]. The potential of secondary automated databases for observational epidemiological studies is widely acknowledged; however, their use is not without challenges, and many quality requirements and methodological pitfalls must be considered [4].

Meta-analysis represents one of the most valuable tools for assessing drug effects as it may lead to the best

(c) The Author(s). 2018 Open Access This article is distributed under the terms of the Creative Commons Attribution 4.0 International License (http://creativecommons.org/licenses/by/4.0/), which permits unrestricted use, distribution, and reproduction in any medium, provided you give appropriate credit to the original author(s) and the source, provide a link to the Creative Commons license, and indicate if changes were made. The Creative Commons Public Domain Dedication waiver (http://creativecommons.org/publicdomain/zero/1.0/) applies to the data made available in this article, unless otherwise stated. 
evidence possible in epidemiology [5]. Consequently, its use for making relevant clinical and regulatory decisions on the safety and efficacy of drugs is dramatically increasing [6]. Existence of heterogeneity in a given meta-analysis is a feature that needs to be carefully described by analyzing the possible factors responsible for generating it [7]. In this regard, the results of a recent study [8] show that whether the origin of the data (primary vs secondary) is explored as a potential cause of heterogeneity may change the conclusions of a meta-analysis due to an effect modification [9]. Thus, considering the source of data as a variable in sensitivity and subgroup analyses, or meta-regression analyses, seems crucial to avoid misleading conclusions in meta-analyses of drug effects.

Given the evidence noted $[8,9]$, we surveyed published meta-analyses in a selection of high-impact journals over a 6-year period, to assess to what extent the origin of the data, either primary or secondary, is explored as a source of heterogeneity in meta-analyses of observational studies.

\section{Methods}

\section{Meta-analysis selection and data collection process}

General and internal medicine journals with an impact factor $>15$ according to the Web of Science were included in the survey [10]. This method has been widely used to assess quality as well as publication trends in medical journals [11-13]. The rationale is that meta-analyses published in high impact journals: (1) are likely to be rigorously performed and reported due to the exhaustive editorial process [12, 14]; and, (2) in general, exert a higher influence on medical practice due to the major role played by these journals in the dissemination of the new medical evidence $[14,15]$. We searched MEDLINE on May 2018 using the search terms "meta-analysis" as publication type and "drug" in any field between January 1, 2012 and May 7, 2018 in the New England Journal of Medicine (NEJM), Lancet, Journal of the American Medical Association (JAMA), British Medical Journal (BMJ), JAMA Internal Medicine (JAMA Intern Med), Annals of Internal Medicine (Ann Intern Med), and Nature Reviews Disease Primers (Nat Rev Dis Primers).

Two investigators (GP-R, FR) independently assessed publications for eligibility. Abstracts were screened and if deemed potentially relevant, full text articles were retrieved. Articles were excluded if they met any of the following conditions: (1) were not a meta-analysis of published studies, (2) no drug effects were evaluated, (3) only randomized clinical trials were included in the meta-analysis (in order to consider observational studies), (4) less than two observational studies were included in the meta-analysis (since with a single study it would not have been possible to calculate a pooled measure). When a meta-analysis included both observational studies and clinical trials, only observational studies were considered.

A data extraction form was developed previously to extract information from articles. Two investigators (GP-R, FR) independently extracted and recorded the information and resolved discrepancies by referring to the original report. If necessary, a third author (AF) was asked to resolve disagreements between the investigators.

When available we extracted the following data from each eligible meta-analysis: first author, publication year, journal, drug(s) exposure and outcome(s); number of individual studies included in the meta-analysis based on each type of data source used (primary vs secondary), for both exposure and outcome assessment; and exposure- and outcome-related variables included in sensitivity, subgroup or meta-regression analyses. We extracted data directly from the tables, figures, text, and supplementary material of the meta-analyses, not from the individual studies.

\section{Assessment of exposure and outcome}

We considered "primary data" the information on drug exposure collected directly by the researchers using interviews - personal or by telephone- or self-administered questionnaires. The origin of the data was also considered primary when objective diagnostic methods were used for the determination of drug exposure (e.g. blood test). "Secondary data" are data that were formerly collected for other purposes than that of the study at hand and that were included in databases on drug prescription (e.g. prescription registers, medical records/charts) and dispensing (e.g. computerized pharmacy records, insurance claims databases). Regarding the outcome assessment, we considered primary data when an objective confirmation is available that endorses them (e.g. confirmed by individual medical ad hoc diagnosis, lab test or imaging results). These criteria are based on those commonly used in the risk assessment of bias for observational studies [16-19].

\section{Results}

MEDLINE search results yielded 217 articles from the major general medical journals (3 from NEJM, 46 from Lancet, 26 from JAMA, 85 from BMJ, 19 from JAMA Intern Med, 38 from Ann Intern Med, and 0 from Nat Rev Dis Primers) (see Fig. 1). A total of 194 articles were excluded (see list of excluded articles with reasons for exclusion in Additional file 1) leaving 23 articles to be examined [20-42]. General characteristics of the 23 included meta-analyses are outlined in Table 1.

\section{Source of exposure and outcome data}

Table 2 summarizes the evidence regarding the type of data source included in each meta-analysis, according to the information presented in the data extraction tables of the 


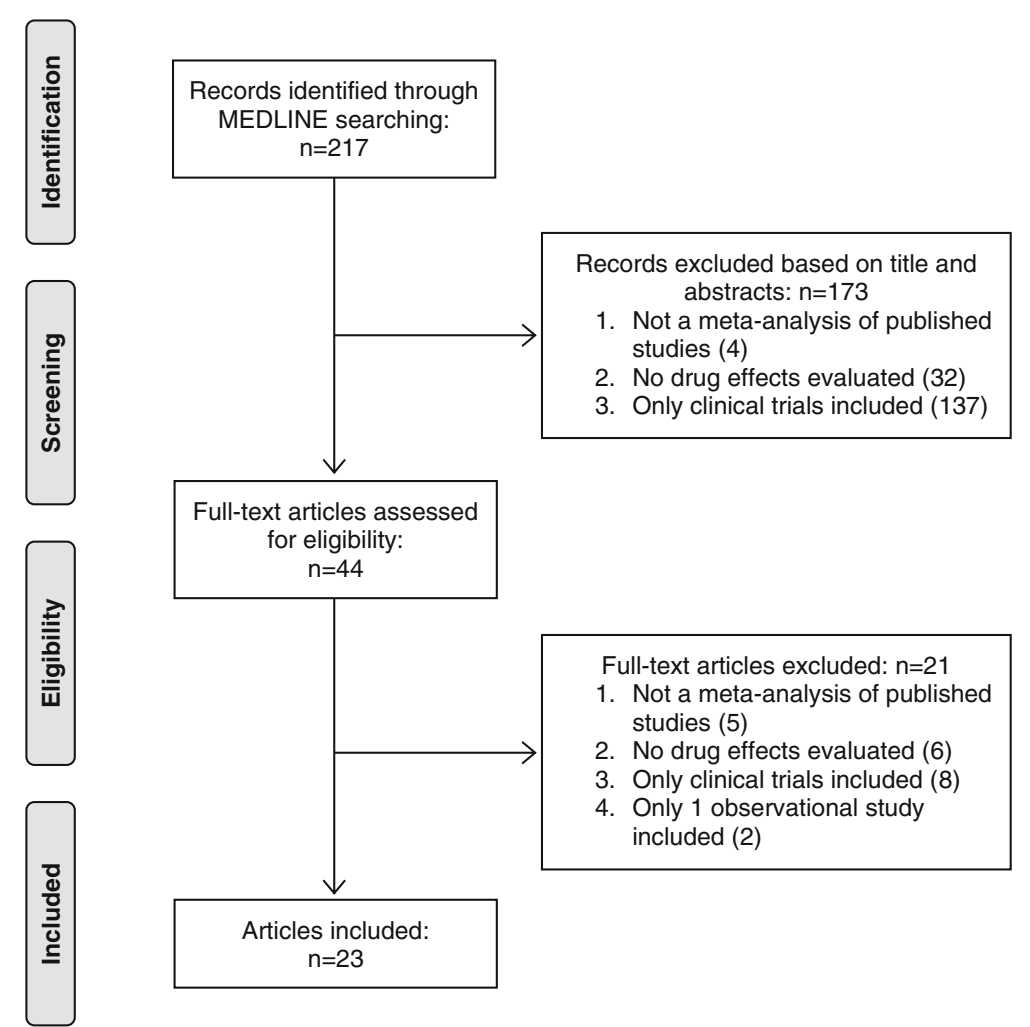

Fig. 1 Flow diagram of literature search results

article. The information was evaluated taking the study design into account. Only eight meta-analyses $[21,24,26,31$, $32,34,38,41]$ reported the source of data, three of them $[31,34,38]$ reporting mixed sources for both the exposure and outcome assessment. Five meta-analyses [21, 24, 26, $32,41]$ reported only secondary sources for the exposure assessment, three of them $[21,24,41]$ reporting as well only secondary sources for the outcome assessment, while in the other two $[26,32]$ only primary and mixed sources for the outcome assessment were reported respectively.

\section{Source of data in the analysis of heterogeneity}

All but two [20,42] of the meta-analyses performed subgroup and/or sensitivity analyses. Although three of them $[23,34,36]$ considered the methods of outcome assessment - type of diagnostic assay used for Clostridium difficile infection, method of venous thrombosis diagnosis confirmation, and type of scale for psychosis symptoms assessment respectively- as stratification variables, only the second referred to the origin of the data. Only five meta-analyses [22, 28, 33, 35, 39] included meta-regression analyses to describe heterogeneity, none of which considered the source of data as an explanatory variable. Other findings for the inclusion of the data source as a variable in the analysis of heterogeneity are presented in Table 3.
We finally assessed if the influence of the data origin on the conclusions of the meta-analyses was discussed by their respective authors. We found that only four meta-analyses [21, 31, 32, 34] noted limitations derived from the type of data source used.

\section{Discussion}

The findings of this research suggest that the origin of the data, either primary or secondary, is underexplored as a source of heterogeneity and an effect modifier in meta-analyses of drug effects published in general medicine journals with high impact. Few meta-analyses reported the source of data and only one [34] of the articles included in our survey compared and discussed the meta-analysis results considering the different sources of data.

Although it is usual to consider the design of the individual studies (i.e. case-control, cohort or experimental studies) in the analysis of the heterogeneity of a meta-analysis [43, 44], the type of data source (primary vs secondary) is still rarely used for this purpose $[9,45]$. In fact, the current reporting guidelines for meta-analyses, such as MOOSE (Meta-analysis Of Observational Studies in Epidemiology) [18] or PRISMA (Preferred Reporting Items for Systematic reviews and Meta-Analyses) [46, 47], do not recommend that authors specifically report the origin of the data. This is probably due to the close 


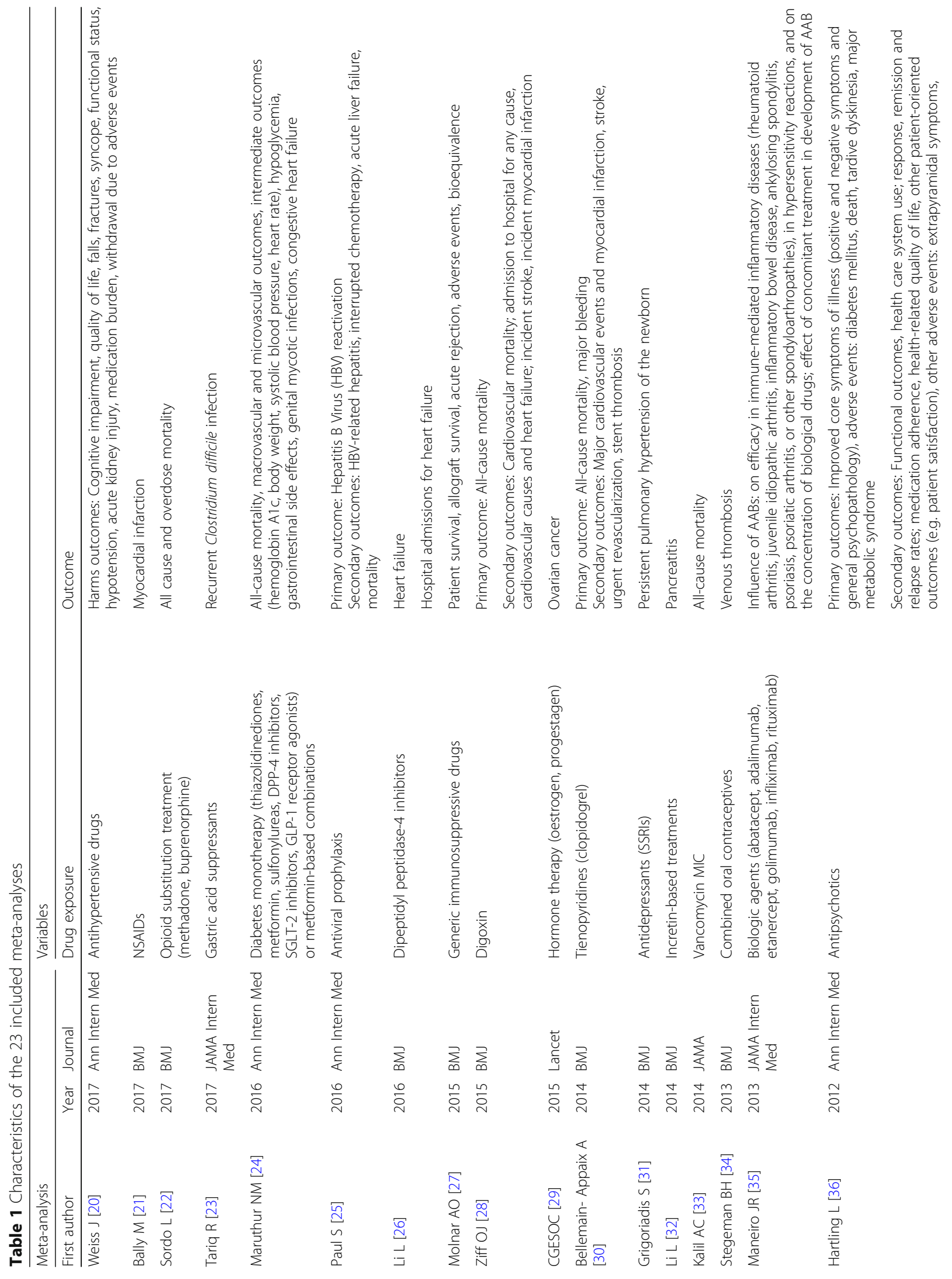




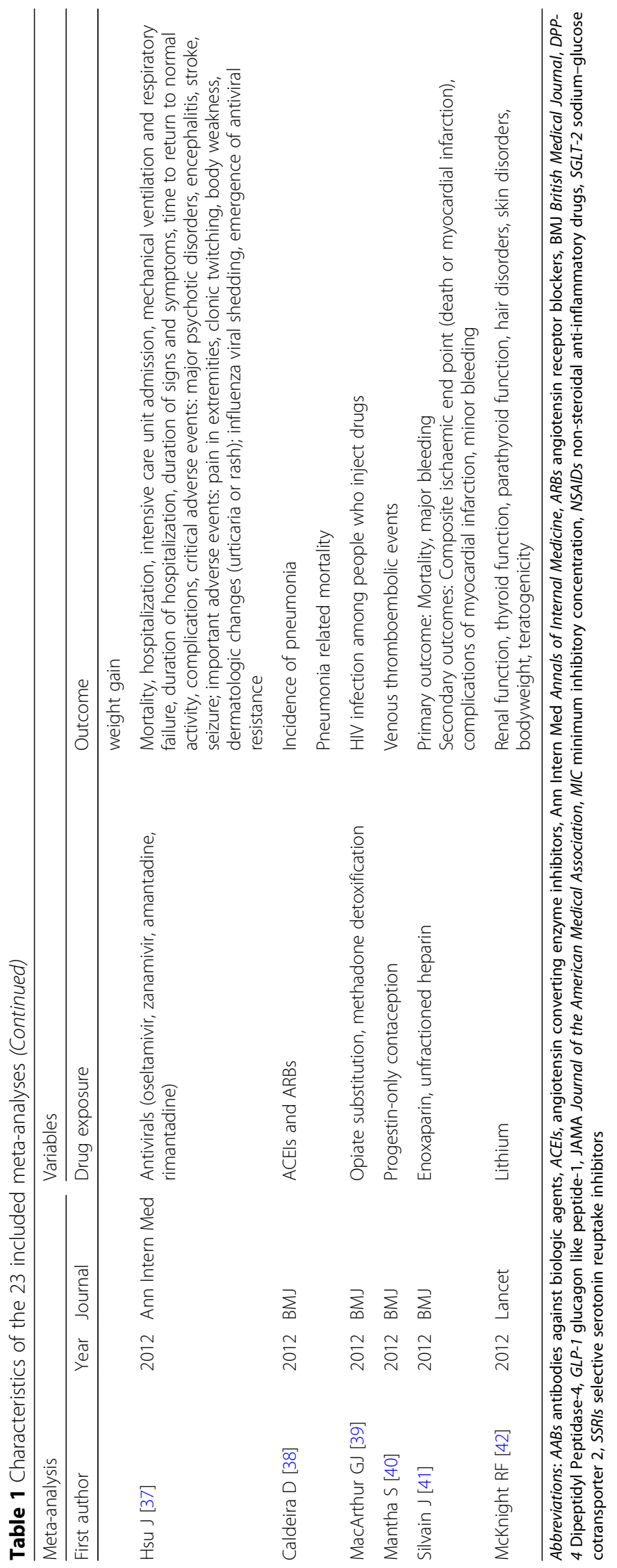


Table 2 Reporting of the data source in the data extraction tables of the included meta-analyses

\begin{tabular}{|c|c|c|c|c|c|c|c|c|c|c|c|c|c|c|}
\hline \multirow[t]{3}{*}{ Meta-analysis (MA) } & \multicolumn{7}{|c|}{ Exposure assessment } & \multicolumn{7}{|c|}{ Outcome assessment } \\
\hline & \multirow{2}{*}{$\begin{array}{l}\text { Data } \\
\text { source } \\
\text { presented } \\
\text { in MA }\end{array}$} & \multicolumn{3}{|c|}{$\begin{array}{l}\text { Cohort studies } \\
\text { (n) }\end{array}$} & \multicolumn{3}{|c|}{$\begin{array}{l}\text { Case-control studies } \\
\text { (n) }\end{array}$} & \multirow{2}{*}{$\begin{array}{l}\text { Data } \\
\text { source } \\
\text { presented } \\
\text { in MA }\end{array}$} & \multicolumn{3}{|c|}{$\begin{array}{l}\text { Cohort studies } \\
\text { (n) }\end{array}$} & \multicolumn{3}{|c|}{$\begin{array}{l}\text { Case-control studies } \\
\text { (n) }\end{array}$} \\
\hline & & 1ry & 2 ry & NR & 1ry & $2 r y$ & NR & & 1ry & 2 ry & NR & 1ry & 2 ry & NR \\
\hline $\begin{array}{l}\text { Weiss J [20] } \\
\text { Harms outcomes }\end{array}$ & No & & . & & . & . & . & No & & . & & . & . & \\
\hline Bally M [21] & Yes & 0 & $3^{b}$ & 0 & 0 & 1 & 0 & Yes & 0 & $3^{\mathrm{b}}$ & 0 & 0 & 1 & 0 \\
\hline Sordo L [22] & $\mathrm{No}^{\mathrm{a}}$ & . & & . & . & . & . & $\mathrm{No}^{\mathrm{a}}$ & . & & . & . & & . \\
\hline Tariq R [23] & $\mathrm{No}^{\mathrm{ac}}$ & . & . & . & . & . & . & $\mathrm{No}^{\mathrm{a}}$ & . & . & . & & . & . \\
\hline Maruthur NM [24] & Yes $^{d}$ & 0 & 3 & 0 & . & . & . & Yes $^{d}$ & 0 & 3 & 0 & . & & . \\
\hline Paul S [25] & $\mathrm{No}^{\mathrm{a}}$ & . & . & r & . & . & . & $\mathrm{No}^{\mathrm{a}}$ & 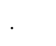 & . & . & & . & $\cdot$ \\
\hline $\begin{array}{l}\text { Li L }[26] \\
\text { Heart failure }\end{array}$ & Yes & 0 & 1 & 2 & 0 & 0 & 1 & Yes & 1 & 0 & 2 & 0 & 0 & 1 \\
\hline $\begin{array}{l}\text { Li L [26] } \\
\text { Hospital admissions for heart failure }\end{array}$ & Yes & 0 & 0 & 6 & 0 & 0 & 2 & Yes & 3 & 0 & 3 & 0 & 0 & 2 \\
\hline Molnar AO [27] & $\mathrm{No}^{\mathrm{a}}$ & . & . & & . & . & . & $\mathrm{No}^{\mathrm{a}}$ & & . & & & . & \\
\hline Ziff OJ [28] & $\mathrm{No}^{\mathrm{a}}$ & . & . & . & . & & . & $\mathrm{No}^{\mathrm{a}}$ & . & . & . & & . & . \\
\hline CGESOC [29] & No & . & . & . & . & . & . & No & . & . & . & & . & . \\
\hline Bellemain-Appaix A [30] & $\mathrm{No}^{\mathrm{a}}$ & . & . & . & . & & . & $\mathrm{No}^{\mathrm{a}}$ & . & . & . & & . & . \\
\hline Grigoriadis S [31] & Yes & 2 & 3 & 0 & 1 & 1 & 0 & Yes & 4 & 1 & 0 & 2 & 0 & 0 \\
\hline Li L [32] & Yes & 0 & 1 & 2 & 0 & 1 & 1 & Yes & 1 & 2 & 0 & 0 & 0 & 2 \\
\hline Kalil AC [33] & No & . & & . & . & . & . & No & . & & . & & . & . \\
\hline Stegeman BH [34] & Yes & 0 & 9 & 0 & 8 & 8 & 1 & Yes & 4 & 5 & 0 & 5 & 12 & 0 \\
\hline Maneiro JR [35] & $\mathrm{No}^{\mathrm{a}}$ & . & . & . & . & & . & $\mathrm{No}^{\mathrm{a}}$ & . & . & $\cdot$ & & . & . \\
\hline Hartling L [36] & No & . & . & . & . & . & . & No & . & . & . & & . & . \\
\hline Hsu J [37] & $\mathrm{No}^{\mathrm{a}}$ & . & . & . & . & & . & $\mathrm{No}^{\mathrm{a}}$ & . & . & . & & . & . \\
\hline Caldeira D [38] & Yes & 2 & 2 & 7 & 0 & 7 & 1 & Yes & 0 & 1 & 10 & 3 & 1 & 4 \\
\hline MacArthur GJ [39] & $\mathrm{No}^{\mathrm{a}}$ & . & . & . & . & & . & $\mathrm{No}^{\mathrm{a}}$ & . & . & . & & . & . \\
\hline Mantha S [40] & No & . & . & r. & . & . & . & No & . & . & . & & . & \\
\hline Silvain J [41] & Yes & 0 & 7 & 0 & . & & . & Yes & 0 & 7 & 0 & & . & . \\
\hline McKnight RF [42] & No & . & . & & . & . & . & No & & . & & & . & \\
\hline
\end{tabular}

Abbreviations: 1ry number of individual studies in each MA based on primary data sources, 2ry number of individual studies in each MA based on secondary data sources, $N R$ number of individual studies in each MA with not reported data source

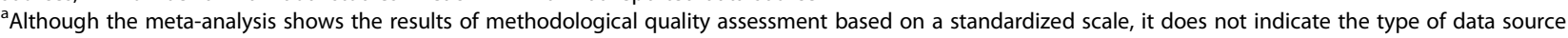
used for each individual observational study included in the meta-analysis

${ }^{\mathrm{b}}$ Cohort with nested case-control analysis

'The meta-analysis reports that most of the included observational studies assessed medication exposure through a review of medical records

${ }^{\mathrm{d} T h e}$ meta-analysis reports only data from high-quality observational studies

relationship that exists between the study design and the type of data source used, despite the fact that each criterion has its own basis. Performing this additional analysis is a simple task that involves no additional cost. Failure to do so may lead to diverging conclusions [8].

Conclusions about the effects of a drug that are derived from studies based exclusively on data from secondary sources may be dicey, among other reasons, because no information is collected on consumption of over-the-counter drugs (i.e. drugs that individuals can buy without a prescription) [48] and/or out-of-pocket expenses for prescription drugs (i.e. costs that individuals pay out of their own cash reserves) [49]. In the health care and insurance context, out-of-pocket expenses usually refer to deductibles, co-payments or co-insurance. Figure 2 shows the model that we propose to describe the relationship between the different data records according to their origin, including the possible loss of information (susceptible to be registered only through primary research).

Failure to take these situations into account may lead to exposure measurement bias [48, 49]. Consumption of a drug may be underestimated when only prescription data 


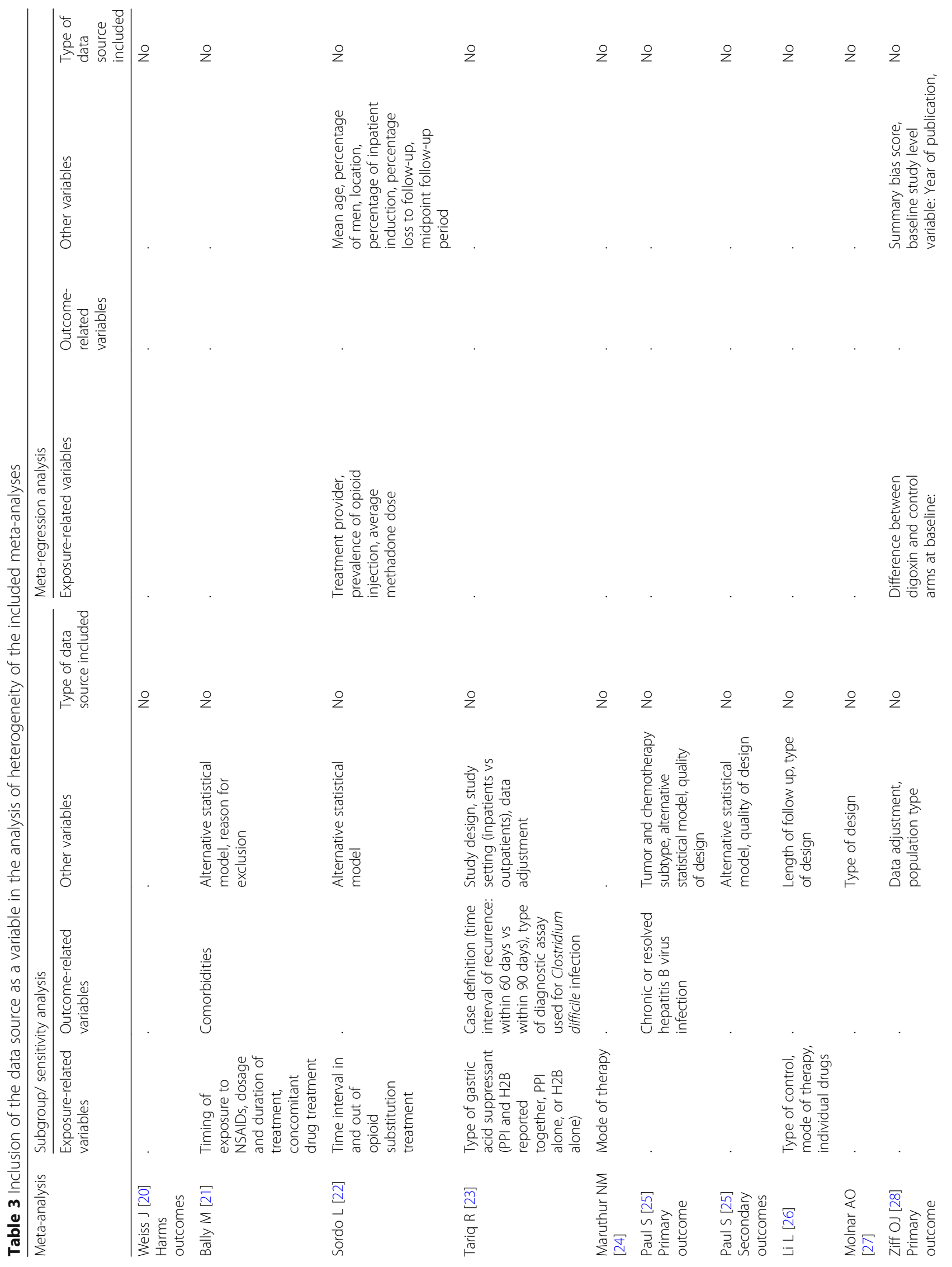




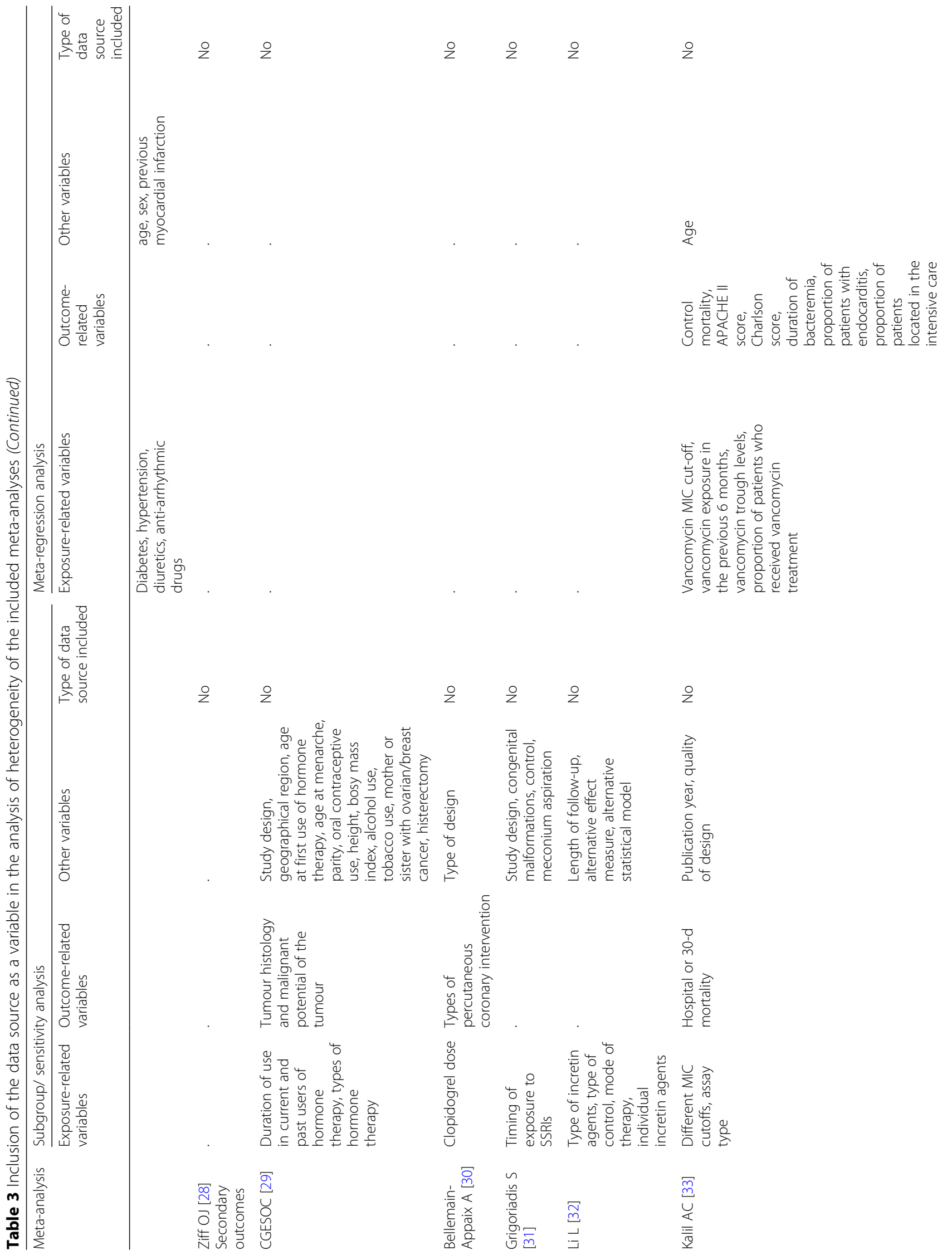




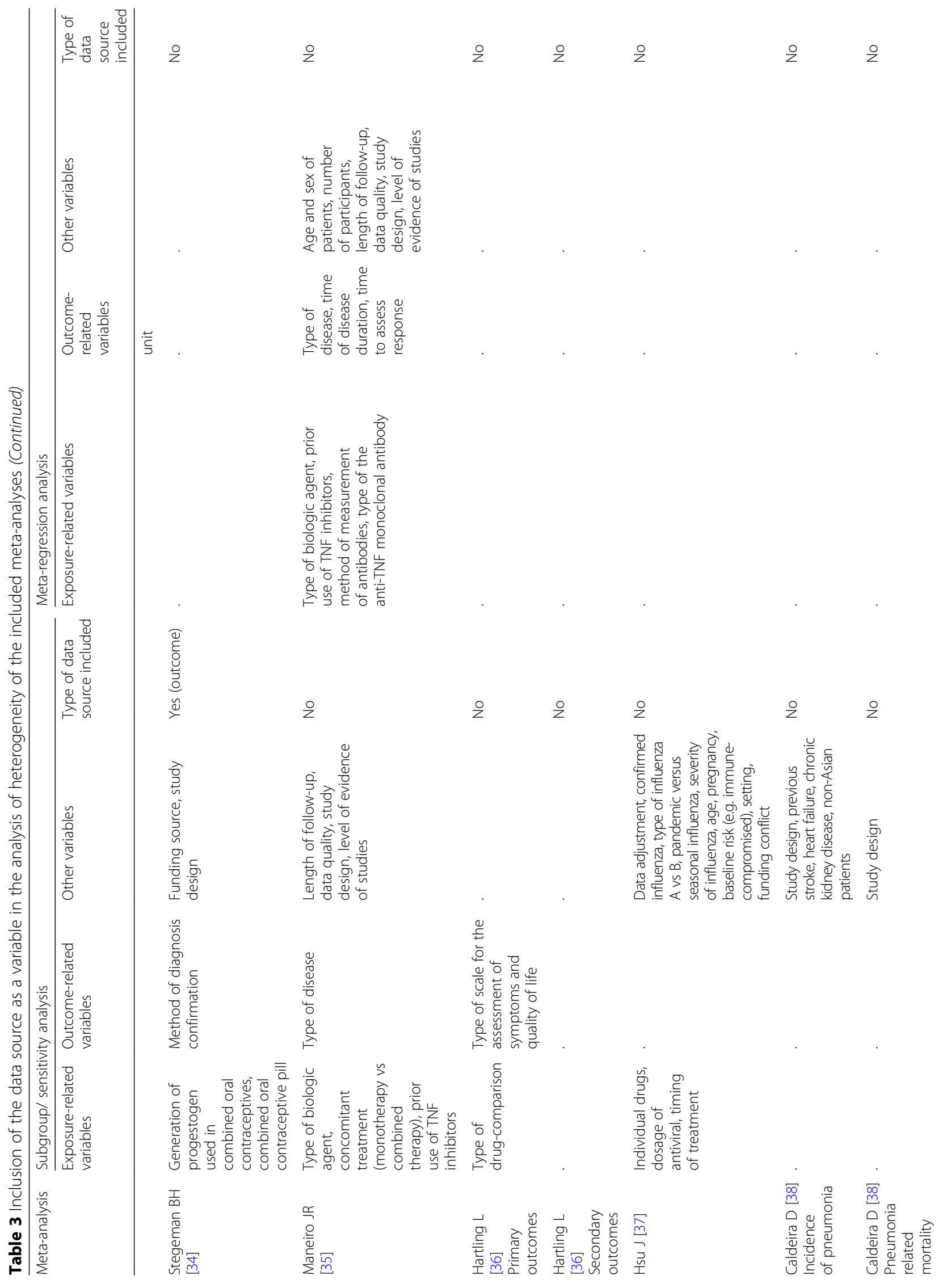




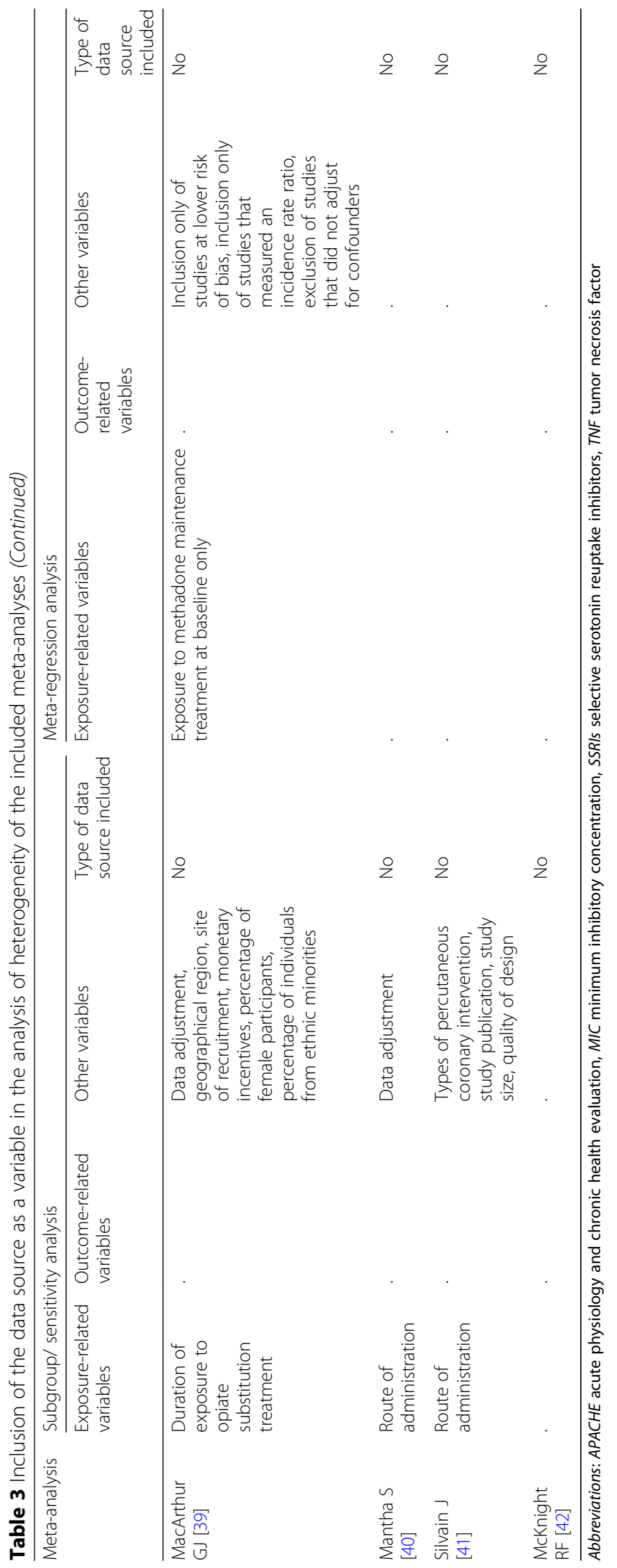




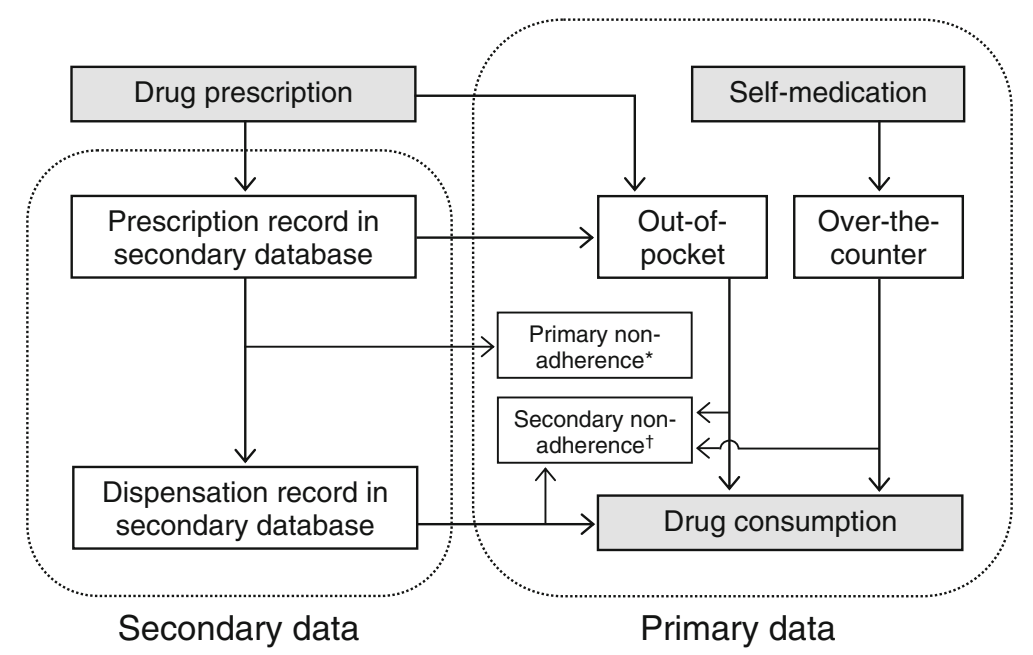

Fig. 2 Conceptual model of individual data recording. ${ }^{*}$ Never dispensed. ${ }^{\dagger}$ Absence of dispensing of successive prescriptions (or self-medication) among patients with primary adherence, or inadequate secondary adherence

is used as secondary source without additionally considering unregistered consumption, such as over-the-counter consumption (e.g. oral contraceptives [34, 50]), that may only be available from a primary database. Alternatively, this may occur when dispensing data for billing purposes (reimbursement) are used for clinical research, if out-of-pocket expenses are not considered (see Fig. 2). The portion of the medical bill that the insurance company does not cover, and that the individual must pay on his own, is unlikely to be recorded. Data on the sale of over-the-counter drugs will also not be available in this scenario.

The reverse situation may also occur and consumption may be overestimated when only prescription data is used, if the prescribed drug is not dispensed by the pharmacist; or when dispensing data is used, if the drug is not really consumed by the patient. While primary non-adherence occurs when the patient does not pick up the medication after the first prescription, secondary non-adherence refers to the absence of dispensing of successive prescriptions among patients with primary adherence, or to inadequate secondary adherence (i.e. $\geq 20 \%$ of time without adequate medication) [51] (see Fig. 2). In some diseases the medication adherence is very low [52-55], with percentages of primary non-adherence (never dispensed) that exceed 30\% [56]. It should be noted that the impact of non-adherence varies from medication to medication. Therefore, it must be defined and measured in the context of a particular therapy [57].

Moreover, failing to take into consideration the portion of consumption due to over-the-counter and/or out-of-pocket expenses may lead to confounding, as that variable may be related to the socio-economic level and/ or to the potential of access to the health system [58], which are independent risk factors of adverse outcomes of some medications (e.g. myocardial infarction [21, 28, $30,41])$. Given the presence of high-deductible health plans and the high co-insurance rate for some drugs, cost-sharing may deter clinically vulnerable patients from initiating essential medications, thus negatively affecting patient adherence [59,60].

Outcome misclassification may also give rise to measurement bias and heterogeneity [61]. This occurs, for example, in the meta-analysis that evaluates the relationship between combined oral contraceptives and the risk of venous thrombosis [34]. In the studies without objective confirmation of the outcome, the women were classified erroneously regardless of the use of contraceptives. This led to a non-differential misclassification that may have underestimated the drug-outcome relationship, especially when the third generation of progestogen is analysed: Risk ratio (RR) primary data $=6.2$ (95\% confidence interval (CI) 5.2-7.4), RR secondary data $=3.0$ (95\% CI 1.7-5.4) [34].

On the one hand, medical records are often considered as being the best information source for outcome variables. However, they present important limitations in the recording of medications taken by patients [62]. On the other hand, dispensing records show more detailed data on the measurement of drug exposure. However, they do not record the over-the-counter or out-of-pocket drug consumption at an individual level [48, 49], apart from offering unreliable data on outcome variables $[62,63]$.

\section{Limitations}

The first limitation of this research is that its findings may not be applicable to journals not included in our survey such as journals with low impact factor. 
Despite the widespread use of the impact factor metric [64], this method has inherent weaknesses [65, 66]. However, meta-analyses published in high impact general medicine journals are likely to be most rigorously performed and reported due to their greater availability of resources and procedures [12, 14]. It is then expected that the overall reporting quality of articles published in other lesser-known journals will be similar. Another limitation would be related to the limited search period. In this sense, and given that the general tendency is the improvement of the methodology of published meta-analyses [67, 68], we find no reason to suspect that the adverse conclusions could be different before the period from 2012 to 2018. Although it exceeds the objective of this research, one last limitation may be the inability to reanalyse the included meta-analyses stratifying by the type of data source since our study design restricts the conclusions to the published data of the meta-analyses, which were insufficiently reported, or the number of individual studies in each stratum was insufficient to calculate a pooled measure (see Table 2).

\section{Conclusions}

Owing to automated capture of data on drug prescription and dispensing that are used for billing and other administration purposes, as well as to the implementation of electronic medical records, secondary databases have generated enormous possibilities. However, neither their limitations, nor the risk of bias that they pose should be overlooked [69]. Thus, researchers should consider the link between administrative databases and medical records, as well as the advisability of combining secondary and primary data in order to minimize the occurrence of biases due to the use of any of these databases.

No source of heterogeneity in a meta-analysis should ever be considered alone but always as part of an interconnected set of potential questions to be addressed. In particular, the origin of the data, either primary or secondary, is insufficiently explored as a source of heterogeneity in meta-analyses of drug effects, even in those published in high impact general medicine journals. Thus, we believe that authors should systematically include the source of data as an additional variable in subgroup and sensitivity analyses, or meta-regression analyses, and discuss its influence on the meta-analysis results. Likewise, reviewers, editors and future guidelines should also consider the origin of the data as a potential cause of heterogeneity in meta-analyses of observational studies that include both primary and secondary data. Failure to do this may lead to misleading conclusions, with negative effects on clinical and regulatory decisions.

\section{Additional file}

Additional file 1: Excluded articles. List of articles excluded with reasons for exclusion. (PDF $247 \mathrm{~kb}$ )

\section{Abbreviations}

Ann Intern Med: Annals of Internal Medicine; BMJ: British Medical Journal; Cl: Confidence Interval; JAMA Intern Med: JAMA Internal Medicine; JAMA: Journal of the American Medical Association; MOOSE: Meta-analysis Of Observational Studies in Epidemiology; Nat Rev Dis Primers: Nature Reviews Disease Primers; NEJM: New England Journal of Medicine; PRISMA: Preferred Reporting Items for Systematic reviews and Meta-Analyses; RR: Risk ratio; VS: Versus

Funding

This study received no funding from the public, commercial or not-for-profit sectors.

\section{Availability of data and materials}

All data generated or analysed during this study are included in this published article.

\section{Authors' contributions}

AF and GP-R contributed to study conception and design. GP-R, FR and AF contributed to searching, screening, data collection and analyses. GP-R was responsible for drafting the manuscript. FR, MTH, BT and AF provided comments and made several revisions of the manuscript. All authors read and approved the final version.

Ethics approval and consent to participate

Not applicable.

Consent for publication

Not applicable.

\section{Competing interests}

The authors declare that they no competing interests.

\section{Publisher's Note}

Springer Nature remains neutral with regard to jurisdictional claims in published maps and institutional affiliations.

\section{Author details}

${ }^{1}$ Department of Preventive Medicine and Public Health, University of Santiago de Compostela, c/ San Francisco s/n, 15786 Santiago de Compostela, A Coruña, Spain. ${ }^{2}$ Health Research Institute of Santiago de Compostela (Instituto de Investigación Sanitaria de Santiago de Compostela - IDIS), Clinical University Hospital of Santiago de Compostela, 15706 Santiago de Compostela, Spain. ${ }^{3}$ Research Unit for Inland Development, Polytechnic of Guarda (Unidade de Investigação para o Desenvolvimento do Interior - UDI/IPG), 6300-559 Guarda, Portugal. ${ }^{4}$ Health Sciences Research Centre, University of Beira Interior (Centro de Investigação em Ciências da Saúde - CICS/UBI), 6200-506 Covilhã, Portugal. ${ }^{5}$ Department of Medical Sciences \& Institute for Biomedicine - iBiMED, University of Aveiro, 3810-193 Aveiro, Portugal. ${ }^{6}$ Higher Polytechnic \& University Education Co-operative (Cooperativa de Ensino Superior Politécnico e Universitário - CESPU), Institute for Advanced Research \& Training in Health Sciences \& Technologies, 4585-116 Gandra, Portugal. ${ }^{7}$ Consortium for Biomedical Research in Epidemiology \& Public Health (CIBER en Epidemiología y Salud Pública (IBERESP), Santiago de Compostela, Spain.

Received: 1 March 2018 Accepted: 18 September 2018

Published online: 27 September 2018

References

1. Terris DD, Litaker DG, Koroukian SM. Health state information derived from secondary databases is affected by multiple sources of bias. J Clin Epidemiol. 2007;60:734-41. 
2. Schneeweiss S. Understanding secondary databases: a commentary on "sources of bias for health state characteristics in secondary databases". J Clin Epidemiol. 2007;60:648-50.

3. Schneeweiss S, Avorn J. A review of uses of health care utilization databases for epidemiologic research on therapeutics. J Clin Epidemiol. 2005:58:323-37.

4. Knottnerus JA, Tugwell P. Requirements for utilizing health care-based data sources for research. J Clin Epidemiol. 2011;64:1051-3.

5. Berlin JA, Golub RM. Meta-analysis as evidence: building a better pyramid. JAMA. 2014;312:603-6.

6. Blettner M, Schlattmann P. Meta-analysis in epidemiology. In: Ahrens W, Pigeot I, editors. Handbook of epidemiology. Berlin: Springer; 2005. p. 829-59.

7. Higgins JPT. Heterogeneity in meta-analysis should be expected and appropriately quantified. Int J Epidemiol. 2008;37:1158-60.

8. Prada-Ramallal G, Takkouche B, Figueiras A. Diverging conclusions from the same meta-analysis in drug safety: source of data (primary versus secondary) takes a toll. Drug Saf. 2017;40:351-8.

9. Madigan D, Ryan PB, Schuemie M, Stang PE, Overhage JM, Hartzema AG, et al. Evaluating the impact of database heterogeneity on observational study results. Am J Epidemiol. 2013;178:645-51.

10. InCites Journal Citation Reports. Science citation index expanded medicine. General \& Internal Thomson Reuters. https://jcr.incites. thomsonreuters.com. Accessed 10 Sept 2018.

11. Faggion CM Jr, Bakas NP, Wasiak J. A survey of prevalence of narrative and systematic reviews in five major medical journals. BMC Med Res Methodol. 2017;17:176

12. Hopewell S, Ravaud P, Baron G, Boutron I. Effect of editors' implementation of CONSORT guidelines on the reporting of abstracts in high impact medical journals: interrupted time series analysis. BMJ. 2012;344:e4178,

13. Blanc $X$, Collet $T H$, Auer $R$, Fischer $R$, Locatelli I, Iriarte $P$, et al. Publication trends of shared decision making in 15 high impact medical journals: a full-text review with bibliometric analysis. BMC Med Inform Decis Mak. 2014;14:71.

14. Rehal S, Morris TP, Fielding K, Carpenter JR, Phillips PP. Non-inferiority trials: are they inferior? A systematic review of reporting in major medical journals. BMJ Open. 2016;6:e12594.

15. Callaham M, Wears RL, Weber E. Journal prestige, publication bias, and other characteristics associated with citation of published studies in peerreviewed journals. JAMA. 2002;287:2847-50.

16. Kim SY, Park JE, Lee YJ, Seo HJ, Sheen SS, Hahn S, et al. Testing a tool for assessing the risk of bias for nonrandomized studies showed moderate reliability and promising validity. J Clin Epidemiol. 2013;66:408-14.

17. Wells GA, Shea B, O'Connell D, Peterson J, Welch V, Losos M, et al. The Newcastle-Ottawa scale (NOS) for assessing the quality of nonrandomised studies in meta-analyses. Ottawa: Univ of Ottawa; 2009. www.ohri.ca/ programs/clinical_epidemiology/oxford.asp. Accessed 10 Sept. 2018

18. Stroup DF, Berlin JA, Morton SC, Olkin I, Williamson GD, Rennie D, et al. Meta-analysis of observational studies in epidemiology: a proposal for reporting. Meta-analysis of observational studies in epidemiology (MOOSE) group. JAMA. 2000;283:2008-12.

19. von Elm E, Altman DG, Egger M, Pocock SJ, Gøtzsche PC, Vandenbroucke JP, et al. The strengthening the reporting of observational studies in epidemiology (STROBE) statement: quidelines for reporting observational studies. Epidemiology. 2007;18:800-4.

20. Weiss J, Freeman M, Low A, Fu R, Kerfoot A, Paynter R, et al. Benefits and harms of intensive blood pressure treatment in adults aged 60 years or older: a systematic review and meta-analysis. Ann Intern Med. 2017;166: 419-29

21. Bally M, Dendukuri N, Rich B, Nadeau L, Helin-Salmivaara A, Garbe E, et al. Risk of acute myocardial infarction with NSAIDs in real world use: bayesian meta-analysis of individual patient data. BMJ. 2017;357:j1909.

22. Sordo L, Barrio G, Bravo MJ, Indave Bl, Degenhardt L, Wiessing L, et al. Mortality risk during and after opioid substitution treatment: systematic review and meta-analysis of cohort studies. BMJ. 2017;357:j1550.

23. Tariq R, Singh S, Gupta A, Pardi DS, Khanna S. Association of Gastric Acid Suppression with Recurrent Clostridium difficile infection: a systematic review and meta-analysis. JAMA Intern Med. 2017;177:784-91.

24. Maruthur NM, Tseng E, Hutfless S, Wilson LM, Suarez-Cuervo C, Berger Z, et al. Diabetes medications as monotherapy or metformin-based combination therapy for type 2 diabetes: a systematic review and meta-analysis. Ann Intern Med. 2016;164:740-51.
25. Paul S, Saxena A, Terrin N, Viveiros K, Balk EM, Wong JB. Hepatitis B virus reactivation and prophylaxis during solid tumor chemotherapy: a systematic review and meta-analysis. Ann Intern Med. 2016;164:30-40.

26. Li L, Li S, Deng K, Liu J, Vandvik PO, Zhao P, et al. Dipeptidyl peptidase-4 inhibitors and risk of heart failure in type 2 diabetes: systematic review and meta-analysis of randomised and observational studies. BMJ. 2016;352:1610.

27. Molnar AO, Fergusson D, Tsampalieros AK, Bennett A, Fergusson N, Ramsay T, et al. Generic immunosuppression in solid organ transplantation: systematic review and meta-analysis. BMJ. 2015;350:h3163.

28. Ziff OJ, Lane DA, Samra M, Griffith M, Kirchhof P, Lip GY, et al. Safety and efficacy of digoxin: systematic review and meta-analysis of observational and controlled trial data. BMJ. 2015;351 h4451. Erratum in: BMJ 2015;351:h4937.

29. Collaborative Group On Epidemiological Studies Of Ovarian Cancer, Beral V, Gaitskell K, Hermon C, Moser K, Reeves G, et al. Menopausal hormone use and ovarian cancer risk: individual participant meta-analysis of 52 epidemiological studies. Lancet. 2015;385:1835-42.

30. Bellemain-Appaix A, Kerneis M, O'Connor SA, Silvain J, Cucherat M, Beygui F, et al. Reappraisal of thienopyridine pretreatment in patients with non-ST elevation acute coronary syndrome: a systematic review and meta-analysis. BMJ. 2014;349:96269

31. Grigoriadis S, Vonderporten EH, Mamisashvili L, Tomlinson G, Dennis CL, Koren $\mathrm{G}$, et al. Prenatal exposure to antidepressants and persistent pulmonary hypertension of the newborn: systematic review and metaanalysis. BMJ. 2014;348:f6932.

32. Li L, Shen J, Bala MM, Busse JW, Ebrahim S, Vandvik PO, et al. Incretin treatment and risk of pancreatitis in patients with type 2 diabetes mellitus: systematic review and meta-analysis of randomised and non-randomised studies. BMJ. 2014;348:g2366.

33. Kalil AC, Van Schooneveld TC, Fey PD, Rupp ME. Association between vancomycin minimum inhibitory concentration and mortality among patients with Staphylococcus aureus bloodstream infections: a systematic review and meta-analysis. JAMA. 2014;312:1552-64.

34. Stegeman BH, de Bastos M, Rosendaal FR, van Hylckama Vlieg A, Helmerhorst FM, Stijnen T, et al. Different combined oral contraceptives and the risk of venous thrombosis: systematic review and network meta-analysis. BMJ. 2013:347:55298.

35. Maneiro JR, Salgado E, Gomez-Reino JJ. Immunogenicity of monoclonal antibodies against tumor necrosis factor used in chronic immune-mediated inflammatory conditions: systematic review and meta-analysis. JAMA Intern Med. 2013;173:1416-28.

36. Hartling L, Abou-Setta AM, Dursun S, Mousavi SS, Pasichnyk D, Newton AS. Antipsychotics in adults with schizophrenia: comparative effectiveness of first-generation versus second-generation medications: a systematic review and meta-analysis. Ann Intern Med. 2012;157:498-511.

37. Hsu J, Santesso N, Mustafa R, Brozek J, Chen YL, Hopkins JP, et al. Antivirals for treatment of influenza: a systematic review and meta-analysis of observational studies. Ann Intern Med. 2012:156:512-24.

38. Caldeira D, Alarcão J, Vaz-Carneiro A, Costa J. Risk of pneumonia associated with use of angiotensin converting enzyme inhibitors and angiotensin receptor blockers: systematic review and meta-analysis. BMJ. 2012;345:e4260.

39. MacArthur GJ, Minozzi S, Martin N, Vickerman P, Deren S, Bruneau J, et al. Opiate substitution treatment and HIV transmission in people who inject drugs: systematic review and meta-analysis. BMJ. 2012;345:e5945.

40. Mantha S, Karp R, Raghavan V, Terrin N, Bauer KA, Zwicker Jl. Assessing the risk of venous thromboembolic events in women taking progestin-only contraception: a meta-analysis. BMJ. 2012;345:e4944.

41. Silvain J, Beygui F, Barthélémy O, Pollack $C \mathrm{Jr}$, Cohen M, Zeymer U, et al. Efficacy and safety of enoxaparin versus unfractionated heparin during percutaneous coronary intervention: systematic review and meta-analysis. BMJ. 2012;344:e553.

42. McKnight RF, Adida M, Budge K, Stockton S, Goodwin GM, Geddes JR. Lithium toxicity profile: a systematic review and meta-analysis. Lancet. 2012;379:721-8.

43. Egger M, Davey Smith G, Schneider M. Systematic reviews of observational studies. In: Egger M, Davey Smith G, Altman DG, editors. Systematic reviews in health care: meta-analysis in context. 2nd ed. London: BMJ Publishing Group; 2001. p. 211-27.

44. Glasziou PP, Sanders SL. Investigating causes of heterogeneity in systematic reviews. Stat Med. 2002;21:1503-11.

45. Seeger J, Daniel GW. Commercial Insurance Databases. In: Strom BL, Kimmel SE, Hennessy S, editors. Pharmacoepidemiology. 5th ed. Chichester, John Wiley \& Sons; 2012. p. 189-208. 
46. Liberati A, Altman DG, Tetzlaff J, Mulrow C, Gøtzsche PC, loannidis JP, et al The PRISMA statement for reporting systematic reviews and meta-analyses of studies that evaluate healthcare interventions: explanation and elaboration. BMJ. 2009;339:b2700.

47. Zorzela L, Loke YK, loannidis JP, Golder S, Santaguida P, Altman DG, et al. PRISMA harms checklist: improving harms reporting in systematic reviews. BMJ. 2016;352:1157.

48. Cohen JM, Wood ME, Hernandez-Diaz S, Nordeng H. Agreement between paternal self-reported medication use and records from a national prescription database. Pharmacoepidemiol Drug Saf. 2018;27:413-21.

49. Gamble JM, McAlister FA, Johnson JA, Eurich DT. Quantifying the impact of drug exposure misclassification due to restrictive drug coverage in administrative databases: a simulation cohort study. Value Health. 2012;15:191-7.

50. Upadhya KK, Santelli JS, Raine-Bennett TR, Kottke MJ, Grossman D. Over-thecounter access to oral contraceptives for adolescents. J Adolesc Health. 2017;60:634-40.

51. Raebel MA, Schmittdiel J, Karter AJ, Konieczny JL, Steiner JF. Standardizing terminology and definitions of medication adherence and persistence in research employing electronic databases. Med Care. 2013;51(Suppl 3):S11-21.

52. Wu AC, Butler MG, Li L, Fung V, Kharbanda EO, Larkin EK, et al. Primary adherence to controller medications for asthma is poor. Ann Am Thorac Soc. 2015:12:161-6.

53. Fallis BA, Dhalla IA, Klemensberg J, Bell CM. Primary medication nonadherence after discharge from a general internal medicine service. PLoS One. 2013;8:e61735.

54. Anderson KL, Dothard EH, Huang KE, Feldman SR. Frequency of primary nonadherence to acne treatment. JAMA Dermatol. 2015;151:623-6.

55. Fischer MA, Stedman MR, Lii J, Vogeli C, Shrank WH, Brookhart MA, et al. Primary medication non-adherence: analysis of 195,930 electronic prescriptions. J Gen Intern Med. 2010;25:284-90.

56. Tamblyn R, Eguale T, Huang A, Winslade N, Doran P. The incidence and determinants of primary nonadherence with prescribed medication in primary care: a cohort study. Ann Intern Med. 2014;160:441-50.

57. Kolandaivelu K, Leiden BB, O'Gara PT, Bhatt DL. Non-adherence to cardiovascular medications. Eur Heart J. 2014;35:3267-76.

58. Kirkeby MJ, Hansen CD, Andersen JH. Socio-economic differences in use of prescribed and over-the-counter medicine for pain and psychological problems among Danish adolescents--a longitudinal study. Eur J Pediatr. 2014;173:1147-55.

59. Mukherjee K, Kamal KM. Sociodemographic determinants of out-of-pocket expenditures for patients using prescription drugs for rheumatoid arthritis. Am Health Drug Benefits. 2017;10:7-15.

60. Karter AJ, Parker MM, Solomon MD, Lyles CR, Adams AS, Moffet HH, et al. Effect of out-of-pocket cost on medication initiation, adherence, and persistence among patients with type 2 diabetes: The Diabetes Study of Northern California (DISTANCE). Health Serv Res. 2018;53:1227-47.

61. Leong A, Dasgupta K, Bernatsky S, Lacaille D, Avina-Zubieta A, Rahme E. Systematic review and meta-analysis of validation studies on a diabetes case definition from health administrative records. PLoS One. 2013;8:e75256.

62. Takahashi Y, Nishida Y, Asai S. Utilization of health care databases for pharmacoepidemiology. Eur J Clin Pharmacol. 2012;68:123-9.

63. Prada-Ramallal G, Takkouche B, Figueiras A. Summarising the evidence for drug safety: a methodological discussion of different meta-analysis approaches. Drug Saf. 2017:40:547-58.

64. Garfield E. The history and meaning of the journal impact factor. JAMA. 2006:295:90-3

65. Seglen PO. Why the impact factor of journals should not be used for evaluating research. BMJ. 1997;314:498-502.

66. Brown $\mathrm{H}$. How impact factors changed medical publishing-and science. BMJ. 2007;334:561-4.

67. Gerber S, Tallon D, Trelle S, Schneider M, Jüni P, Egger M. Bibliographic study showed improving methodology of meta-analyses published in leading journals 1993-2002. J Clin Epidemiol. 2007;60:773-80.

68. Petropoulou M, Nikolakopoulou A, Veroniki AA, Rios P, Vafaei A, Zarin W, et al. Bibliographic study showed improving statistical methodology of network meta-analyses published between 1999 and 2015. J Clin Epidemiol. 2017:82:20-8.

69. Ray WA. Improving automated database studies. Epidemiology. 2011;22:302-4.

Ready to submit your research? Choose BMC and benefit from:

- fast, convenient online submission

- thorough peer review by experienced researchers in your field

- rapid publication on acceptance

- support for research data, including large and complex data types

- gold Open Access which fosters wider collaboration and increased citations

- maximum visibility for your research: over $100 \mathrm{M}$ website views per year

At BMC, research is always in progress.

Learn more biomedcentral.com/submissions 